\title{
Factors Associated with Late Initiation of Antenatal Care among Pregnant Women Attending Antenatal Clinic at Public Health Centers in Kembata Tembaro Zone, Southern Ethiopia
}

\begin{tabular}{|c|c|}
\hline \multicolumn{2}{|l|}{ Tesfalidet Tekelab ${ }^{1 \star}$, Balcha Berhanu $^{2}$} \\
\hline \multicolumn{2}{|c|}{${ }^{1}$ College of Medical and Health Sciences, Wollega University, P.O. Box 395, Nekemte, Ethiopia } \\
\hline Abstract & \\
\hline \multirow{10}{*}{$\begin{array}{l}\text { The purpose of this study was to identify those factors associated with late initiation of } \\
\text { antenatal care among pregnant women attending antenatal clinics in public health centers in } \\
\text { Kembata Tembaro Zone, Ethiopia. A facility based cross-sectional study with supplement of } \\
\text { qualitative data was carried out to collect data from } 401 \text { pregnant women who were } \\
\text { attending antenatal care service at five randomly selected governmental health centres in } \\
\text { Kembata Tembaro Zone from March } 10 \text { to May } 8,2012 \text {. Pretested and structured } \\
\text { questionnaire was used to collect the data and data were entered onto a computer using } \\
\text { Epi-info 3.5.1 statistical program then exported to SPSS Windows version } 16.0 \text { for further } \\
\text { analysis. Binary descriptive statistics and multiple variable regressions were done. This study } \\
\text { showed that prevalence of late entry to antenatal care was } 68.6 \% \text {. The mean timing was } \\
5.5 \pm 1.8 \text { months. Multivariate analysis revealed that age, maternal education, family income, } \\
\text { parity, previous utilization of antenatal care and type of pregnancy remained significant } \\
\text { factors influencing late booking. The findings of this study showed that most women book } \\
\text { antenatal care late. This seems to be because antenatal care is viewed primarily as curative } \\
\text { rather than preventive in the study population. Public enlightenment, health education } \\
\text { coupled with women empowerment would be helpful in reducing the problem. In addition to } \\
\text { that incorporation of the benefits of early booking in the routine antenatal care education. } \\
\text { Copyright@2014 STAR Journal. All Rights Reserved. }\end{array}$} & $\begin{array}{l}\text { Article Histor } \\
\text { Received : } 0\end{array}$ \\
\hline & : 27-03-2014 \\
\hline & Accepted : 28-03- \\
\hline & \\
\hline & Late initiation \\
\hline & \\
\hline & \\
\hline & \\
\hline & \\
\hline & \\
\hline
\end{tabular}

\section{INTRODUCTION}

For all women of reproductive age, especially for pregnant women, utilization of health care services is a key proximate determinant of maternal and infant outcomes, including maternal and infant mortality. The benefits of health care seeking are tremendous particularly in settings and subgroups where the socioeconomic and public health resources are constrained. It is evident that timely antenatal care (ANC) is an opportunity to prevent the direct causes of maternal mortalities and reduction of fetal and neonatal deaths related to obstetric complications. Thus, antenatal care is one of the recommended cares to be provided for pregnant women (Reynolds et al., 2006).

It is estimated that each year approximately one third of a million women worldwide die due to pregnancy related conditions. $99 \%$ of these deaths occur in developing countries and approximately three-quarters of them are considered avoidable (WHO, 2010).In Ethiopia, the levels of maternal and infant mortality and morbidity are among the highest in the world. There are 676 maternal deaths for every 100,000 live births and the infant mortality rate was 59 per 1,000 live births (CSA, 2011).
Many maternal and prenatal deaths occur in women who have received no ANC. A study done on antenatal care estimated that worldwide only $70 \%$ of women ever receive any ANC, whereas in industrialized countries more than $95 \%$ of pregnant women receive ANC (AbouZahr and Wardlaw, 2003).

Despite progress in antenatal care coverage, many countries, particularly in sub-Saharan Africa and South/Southeast Asia, still have unsatisfactory levels of the recommended four or more antenatal care visits. Additionally, many women, particularly in sub-Saharan Africa, tend to wait to start antenatal care until the second or third trimester (Wang et al., 2011).

According to 2011 Ethiopia Demographic and Health Survey (EDHS) results show that 34 percent of women who gave birth received antenatal care from a trained health professional at least once for their last birth. Eleven percent of women made their first ANC visit before the fourth month of pregnancy. Antenatal care from a trained health professional has increased by 6 percent since the 2005 EDHS estimate $28 \%$ (CSA, 2011).

It is very likely that a good number of women will not initiate ANC early enough in pregnancy to follow the full 


\section{Tesfalidet Tekelab and Balcha Berhanu}

basic component of the Focused ANC in Ethiopia (FMoH, 2010). Late ANC initiation may increase the total cost of caring for a pregnant woman. A cost which arises from missed opportunities to prevent or treat problems early in pregnancy (King et al., 2006).

A study conducted on factors influencing antenatal care service utilization in Hadiya Zone of Southern Ethiopia showed that $68.2 \%$ started antenatal care visit during the second trimester of pregnancy (Zeine et al., 2010). Similar study done in Yem special woreda revealed that $49.2 \%$ women made the first antenatal care visit during their second trimester (Bahilu et al., 2009). Various studies have reported factors associated with late entry to ANC, these include demographic and some socioeconomic factors such as maternal age, parity, maternal educational attainment, place of residence, ethnicity and institutional delivery as well as early antenatal care use (Magadi et al., 2000; Overbosch et al., 2004; Magadi et al., 2003; Magadi et al., 2004; Ramet al., 2006; Trinh et al., 2007).

\section{MATERIALS AND METHODS}

\section{Study Area and Period}

The study was conducted in Kembata Tembaro zone in SNNPR. Kembata Tembaro zone administratively existed with seven woredas and one town administration. The population of the zone is estimated to be about 757,029 out of which $85.99 \%$ of the population is rural and $14.01 \%$ of the population is urban residents. 29,524 (3.99\%) of the population are pregnant mothers (Kembata Tembaro Zone, 2011). The study was conducted from March 10 to May 8, 2012.

\section{Study Design and Sample Size}

A facility based cross-sectional study supplemented by qualitative data was used to assess factors associated with late initiation of antenatal care among pregnant women attending antenatal clinic. A sample of 401 pregnant women attending antenatal clinic was participated in the study. The sample size was determined using a formula for estimation of single population proportion with the assumption of $95 \%$ confidence level, margin of error of $5 \%$, a design effect of two and expected proportion of women attending ANC is $86.3 \%$ (Zeine et al., 2010). To compensate the non-response rate, $10 \%$ of the determined sample was added.

\section{Sampling Procedure}

In order to select a fairly representative sample of pregnant women, the selection of health centers were by simple random sampling from each randomly selected four woredas and one administrative town. The sample size was allocated for study facilities using population proportion to sample for each selected health centers. At each health center, the study subjects were recruited when they come for initial or follow-up of ANC service. Every pregnant woman attending ANC clinic who was willing to participate in the study were taken until the required sample size was obtained in respective health centres.

\section{Data Collection Techniques and Procedures}

Interviewer administered questionnaires was employed to collect the data. The questionnaires adopted and modified from EDHS and related thesis works after reviewing relevant literature (CSA, 2011; Tariku et al., 2010). The English version of the questionnaire was
Sci. Technol. Arts Res. J., Jan-March 2014, 3(1): 108-115

translated into Amharic language for better understanding by the data collectors and respondents. The questionnaire then retranslated back to English to check for its consistency. The questionnaires contain sociodemographic factors, obstetric history, health service barrier, knowledge on ANC and pregnancy related complication and other factors related to ANC utilization.

For qualitative, the data were collected from pregnant women and health service provider by using open-ended and responsive questioning technique (in-depth interviews) by principal investigator and the information was obtained through interview recorded on notebook and tape recorder.

\section{Data Quality Control}

Before conducting the main study, pre-test was carried out on $5 \%$ of antenatal care seekers who were not included in the study. Based on the finding of pre-test, data collectors were reoriented and the questionnaire was modified as necessary.

\section{Data Processing and Analysis}

Each completed questionnaire was coded on prearranged coding sheet by the principal investigator to minimize errors. Data were entered onto a computer using Epi-info window version 3.5.1 statistical programs, $10 \%$ of the responses were randomly selected and checked for consistency of the data entry. Then printed frequencies were used to check for outlier and clean data. The data were cleaned accordingly and then exported to SPSS Windows version 16.0 for analysis. Analysis of data was done using two step logistic regression [bivariate and multivariate] to see the effect of the independent variables on the dependent variable by controlling confounders. Statistical significance was evaluated at 95\% levels of significance. Tables, pie chart and bar graphs were used to present the data.

The qualitative data from women and service providers were collected using semi structured interview guide and transcribed immediately after the data collection. The collected data was summarized under the main thematic areas based on the questions that emerged from the data.

\section{Ethical Considerations}

Ethical approval was obtained from the Research and Publications committee of Department of Nursing and Midwifery, College of Medicine and Health Sciences, Addis Ababa University (Ref. No: NMW-89/2004). A formal letter for permission and support was written to the Kembata Tembaro zone Health Bureau and then the Zone was written a letter to respective health center. Informed consent was obtained from each study participant.

\section{RESULTS}

\section{Socio-demographic Characteristics of Respondents}

The response rate for the study was 392 (97.8\%). The mean age of the study participants were $28.3 \pm 5.5$ and their age ranging from 16 to 40 years. The majorities of the respondents were Kembata ethnic group (54.6\%), Protestant $(70.9 \%)$, married or in union $(94.1 \%)$, illiterate $(34.7 \%)$, their husbands' have no formal education (39\%), most $(54.3 \%)$ were house wives. (32.5\%) of the subjects had monthly house hold income less than 400ETB and the median monthly income of the participants was 500 ETB ranging from 50 to 6000 ETB (Table 1). 


\section{Tesfalidet Tekelab and Balcha Berhanu}

The proportion of respondents who made their first ANC within the recommended time (before or at 16 weeks of gestation) is $123(31.4 \%)$ while those who booked late (after 16 weeks of gestation) were $269(68.6 \%)$. The timing of first ANC booking ranges from $1^{\text {st }}$ to $9^{\text {th }}$ months of gestation. The mean timing was 5.5 \pm 1.8 (Figure1).

Of the total respondents $19.6 \%$ were primigravida while $80.4 \%$ were multigravida. $24.2 \%$ of respondents were parity zero, while the rest $75.8 \%$ were parity one and
Sci. Technol. Arts Res. J., Jan-March 2014, 3(1): 108-115

above. $17.6 \%$ of respondents had history of at least one abortion and the rest $82.4 \%$ had no a history of abortion (Table 2).

The reasons for the specific timing of first ANC was reported $29.3 \%$ as perceived correct time, $16.8 \%$ previous experience of timing, $69.1 \%$ due to illness, $28.3 \%$ to confirm pregnancy, $23.2 \%$ busy by other works, $1 \%$ due to economic factor, $5.6 \%$ unplanned pregnancy, and $8.7 \%$ others (Figure 2)

Table 1: Socio-Demographic characteristics of respondents by time of booking, Kembata Tembaro Zone, 2012.

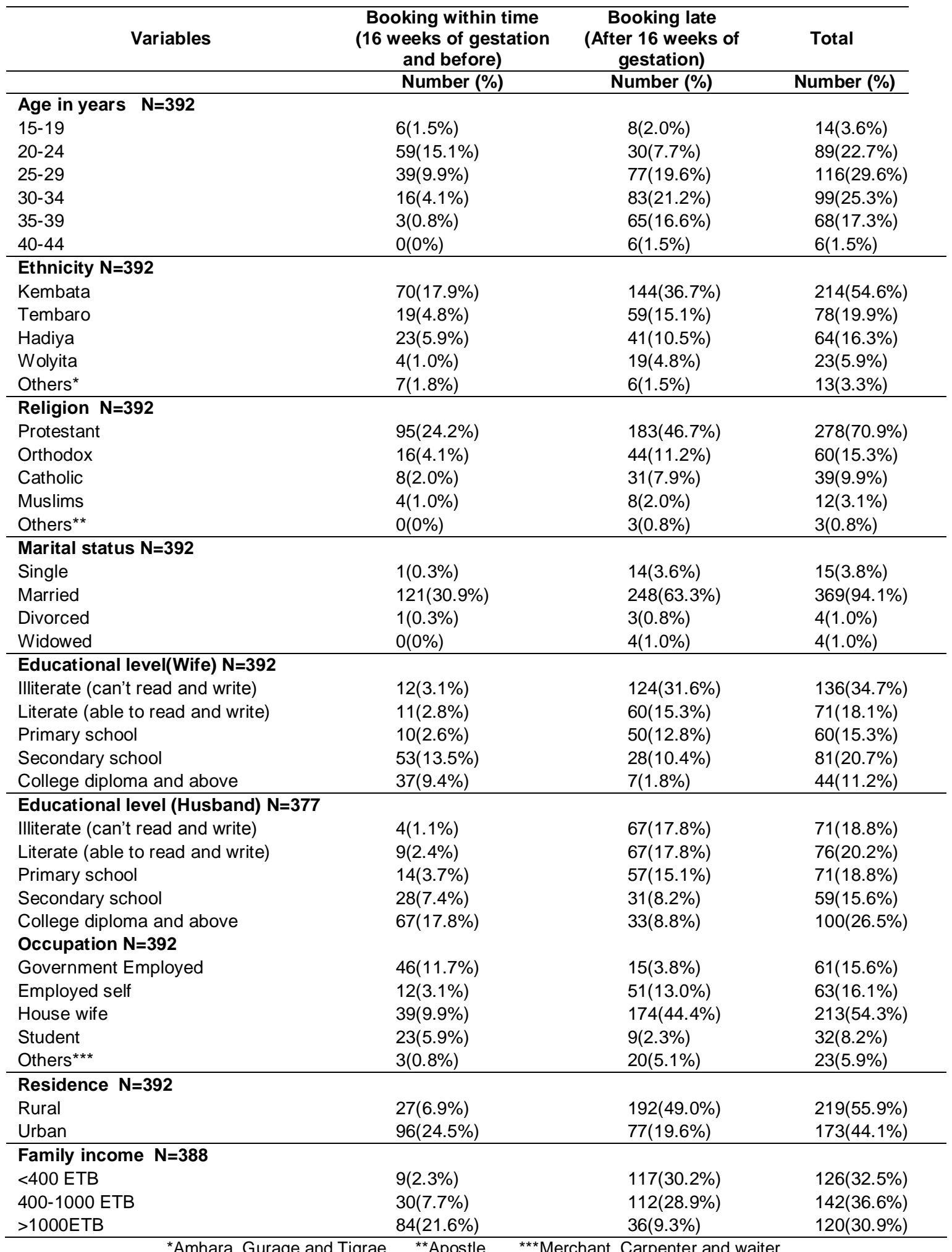




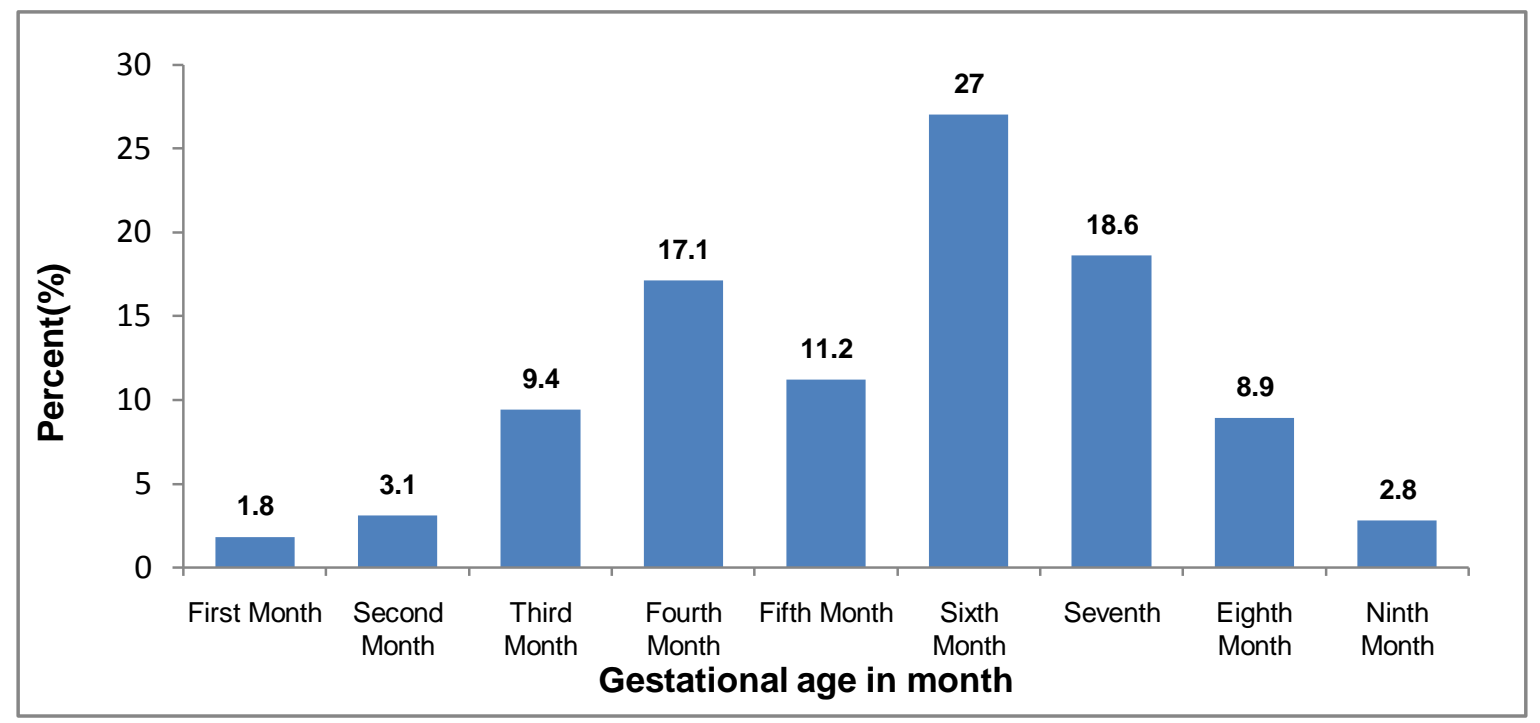

Figure 1: Percentage of respondents by months of gestation booked first ANC, Kembata Tembaro Zone, SNNPR, Ethiopia, 2012.

Table 2: Number of respondents by obstetric history and timing of first ANC, Kembata Tembaro Zone, SNNPR, 2012.

\begin{tabular}{|c|c|c|c|}
\hline Variables & $\begin{array}{l}\text { Booking within time } \\
\text { (16 weeks of gestation } \\
\text { and before) }\end{array}$ & $\begin{array}{c}\text { Booking late } \\
\text { (After } 16 \text { weeks } \\
\text { of gestation) }\end{array}$ & Total \\
\hline & Number (\%) & Number (\%) & Number (\%) \\
\hline \multicolumn{4}{|l|}{ Gravidity $n=392$} \\
\hline One & $43(11.0 \%)$ & $34(8.7 \%)$ & $77(19.6 \%)$ \\
\hline $2-4$ & $75(19.1 \%)$ & $129(32.9 \%)$ & $204(52.0 \%)$ \\
\hline$>=5$ & $5(1.3 \%)$ & $106(27.0 \%)$ & $111(28.3 \%)$ \\
\hline \multicolumn{4}{|l|}{ Parity $n=392$} \\
\hline No parity & $59(15.1 \%)$ & $36(9.2 \%)$ & $95(24.2 \%)$ \\
\hline One or more Parity & $64(16.3 \%)$ & $233(59.4 \%)$ & $297(75.8 \%)$ \\
\hline \multicolumn{4}{|l|}{ History of abortion $n=392$} \\
\hline Yes & $35(8.9 \%)$ & $34(8.7 \%)$ & $69(17.6 \%)$ \\
\hline No & $88(22.4 \%)$ & $235(59.9 \%)$ & $323(82.4 \%)$ \\
\hline \multicolumn{4}{|l|}{ Type of abortion $n=69$} \\
\hline Spontaneous abortion & $34(49.3 \%)$ & $25(36.2 \%)$ & $59(85.5 \%)$ \\
\hline Induced abortion & $2(2.9 \%)$ & $8(11.6 \%)$ & $10(14.5 \%)$ \\
\hline \multicolumn{4}{|l|}{ Birth interval $n=316$} \\
\hline $1-2$ years & $5(1.6 \%)$ & $195(61.7 \%)$ & $200(63.3 \%)$ \\
\hline$>2$ years & $75(23.7 \%)$ & $41(13.0 \%)$ & $116(36.7 \%)$ \\
\hline \multicolumn{4}{|l|}{$\begin{array}{l}\text { Previous utilization of ANC preceding the } \\
\text { current } n=315\end{array}$} \\
\hline Yes & $77(24.4 \%)$ & $126(40.0 \%)$ & $203(64.4 \%)$ \\
\hline No & $3(1.0 \%)$ & $109(34.6 \%)$ & $112(35.6 \%)$ \\
\hline \multicolumn{4}{|c|}{$\begin{array}{l}\text { Time of ANC booking for pervious pregnancy } \\
n=189\end{array}$} \\
\hline Booked before 16 or at weeks of gestation & $50(26.5 \%)$ & $16(8.5 \%)$ & $66(34.9 \%)$ \\
\hline Booked after 16 weeks of gestation & $27(14.3 \%)$ & $96(50.8 \%)$ & $123(65.1 \%)$ \\
\hline \multicolumn{4}{|l|}{ Number of visits for ANC $\quad \mathrm{n}=205$} \\
\hline One Visits & $1(0.5 \%)$ & $7(3.4 \%)$ & $8(3.9 \%)$ \\
\hline Two Visits & $9(4.4 \%)$ & $36(17.6 \%)$ & $45(22.0 \%)$ \\
\hline Three Visits & $20(9.8 \%)$ & $39(19.0 \%)$ & $59(28.8 \%)$ \\
\hline Four and more & $42(20.5 \%)$ & $28(13.7 \%)$ & $70(34.1 \%)$ \\
\hline Do not remember & $7(3.4 \%)$ & $16(7.8 \%)$ & $23(11.2 \%)$ \\
\hline \multicolumn{4}{|l|}{$\begin{array}{l}\text { IIIness experienced for the recent pregnancy } \\
n=392\end{array}$} \\
\hline Yes & $83(21.2 \%)$ & $33(8.4 \%)$ & $116(29.6 \%)$ \\
\hline No & $36(9.2 \%)$ & $209(53.3 \%)$ & $245(62.5 \%)$ \\
\hline Do not remember & $4(1.0 \%)$ & $27(6.9 \%)$ & $31(7.9 \%)$ \\
\hline
\end{tabular}




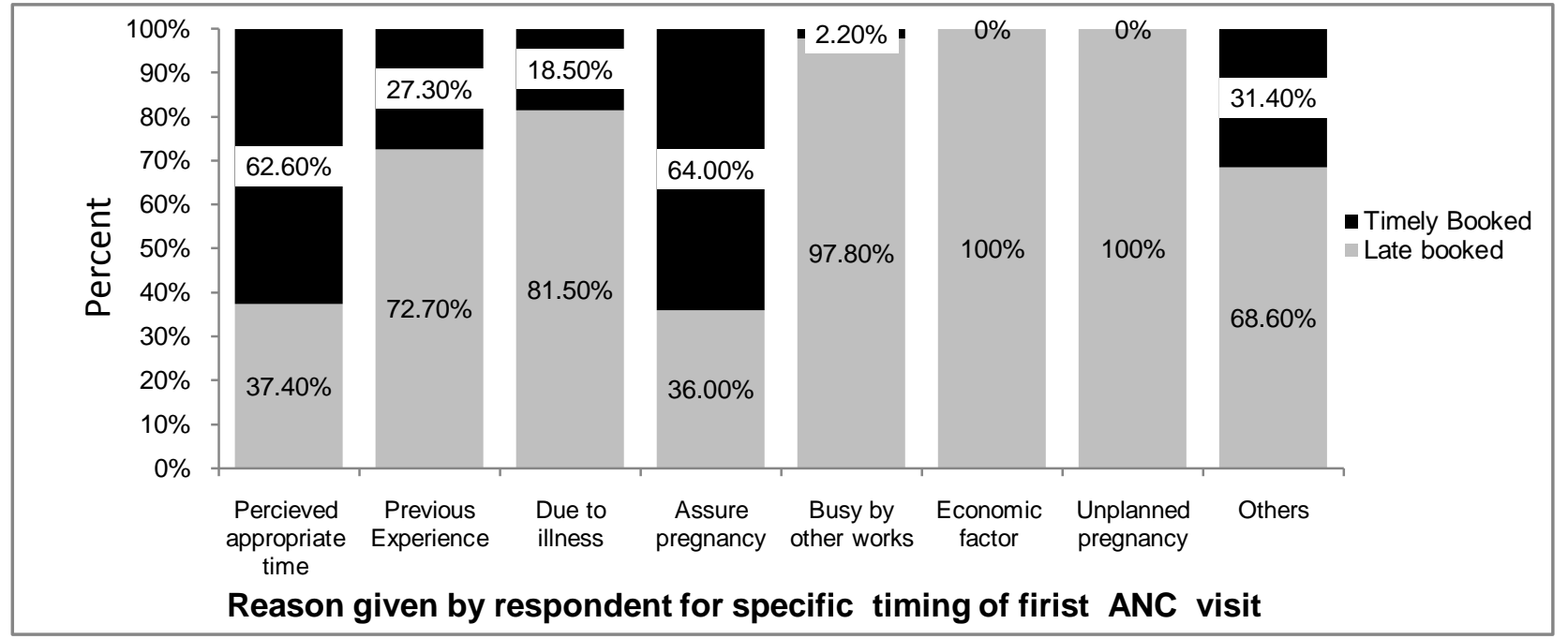

Others=to know the health of the fetus, to know the position of the fetus, to take drugs, for vaccine, advise from health extension workers. \# More than one response is possible.

Figure 2: Reasons given by respondents for specific timing of first ANC booking, Kembata Tembaro Zone, Ethiopia, 2012.

A multivariate analysis involving all associated variables was performed to identify independent predictors of late initiation of ANC. Consequently, age, women's education, family income, parity, previous

utilization of ANC preceding the current pregnancy and type of pregnancy showed significant association with late initiation of ANC even after controlling for confounding factors(Table 3).

Table 3: Association of selected socio- demographic, Obstetrics and other associated factors with timely booking of first ANC, Kembata Tembaro Zone, 2012.

\begin{tabular}{|c|c|c|c|c|}
\hline \multirow[b]{2}{*}{ Variables } & \multicolumn{2}{|c|}{ Time at first visit } & \multirow{2}{*}{$\begin{array}{r}\text { Crude OR } \\
\text { OR(CI) }\end{array}$} & \multirow{2}{*}{$\begin{array}{r}\text { Adjusted OR } \\
\text { OR(Cl) }\end{array}$} \\
\hline & $\begin{array}{l}\text { Booked Timely } \\
\text { (Early) }\end{array}$ & $\begin{array}{l}\text { Booked } \\
\text { late }\end{array}$ & & \\
\hline \multicolumn{5}{|l|}{ Age } \\
\hline$<25$ & $65(16.6 \%)$ & $38(9.7 \%)$ & 1 & 1 \\
\hline$>=25$ & $58(14.8 \%)$ & $231(58.9 \%)$ & $6.81(4.16-11.15)^{\star}$ & $3.04(1.05-8.81)^{*}$ \\
\hline \multicolumn{5}{|l|}{ Women's education } \\
\hline Primary and Below & $33(8.4 \%)$ & $234(59.7 \%)$ & $18.23(10.69-31.11)^{*}$ & $4.62(1.5-14.24)^{*}$ \\
\hline Secondary and above & $90(23.0 \%)$ & $35(8.9 \%)$ & 1 & 1 \\
\hline \multicolumn{5}{|l|}{ Husband education } \\
\hline Primary and Below & $27(7.2 \%)$ & $191(50.7 \%)$ & $10.50(6.27-17.53)^{*}$ & $0.95(0.34-2.65)$ \\
\hline Secondary and above & $95(25.2 \%)$ & $64(17.0 \%)$ & 1 & 1 \\
\hline \multicolumn{5}{|l|}{ Residence } \\
\hline Rural & $27(6.9 \%)$ & $192(49.0 \%)$ & $8.87(5.37-14.65)^{*}$ & $0.64(0.18-2.31)$ \\
\hline Urban & $96(24.5 \%)$ & $77(19.6 \%)$ & 1 & 1 \\
\hline \multicolumn{5}{|l|}{ Occupation } \\
\hline Employed & $58(14.8 \%)$ & $66(16.8 \%)$ & 1 & 1 \\
\hline Unemployed & $65(16.6 \%)$ & $203(51.8 \%)$ & $2.75(1.75-4.30)^{*}$ & $1.01(0.44-2.35)$ \\
\hline \multicolumn{5}{|l|}{ Family income } \\
\hline$<400$ ETB & $9(2.3 \%)$ & $117(30.2 \%)$ & $30.33(13.87-66.33)^{*}$ & $7.01(1.85-26.56)^{*}$ \\
\hline 400-1000 ETB & $30(7.7 \%)$ & $112(28.9 \%)$ & $8.71(4.97-15.23)^{\star}$ & $3.29(1.31-8.28)^{\star}$ \\
\hline$>1000 E T B$ & $84(21.6 \%)$ & $36(9.3 \%)$ & 1 & 1 \\
\hline \multicolumn{5}{|l|}{ Parity } \\
\hline No Parity & $59(15.1 \%)$ & $36(9.2 \%)$ & 1 & 1 \\
\hline Parity one and above & $64(16.3 \%)$ & $233(59.4 \%)$ & $5.97(3.63-9.82)^{*}$ & $161.67(4.35-601)^{*}$ \\
\hline \multicolumn{5}{|l|}{ History of abortion } \\
\hline Yes & $35(8.9 \%)$ & $34(8.7 \%)$ & 1 & 1 \\
\hline No & $88(22.4 \%)$ & $235(59.9 \%)$ & $2.75(1.62-4.68)^{*}$ & $2.23(0.84-5.93)$ \\
\hline \multicolumn{5}{|c|}{ Previous utilization of ANC } \\
\hline Yes & $77(24.4 \%)$ & $126(40.0 \%)$ & 1 & 1 \\
\hline No & $3(1.0 \%)$ & $109(34.6 \%)$ & $22.20(6.81-72.37)^{\star}$ & $15.64(1.99-122.95)^{*}$ \\
\hline \multicolumn{5}{|l|}{$\begin{array}{l}\text { Distance from home to } \\
\text { health institution }\end{array}$} \\
\hline$<60$ & $103(26.3 \%)$ & $98(25.0 \%)$ & 1 & 1 \\
\hline$>=60$ & $20(5.1 \%)$ & $171(43.6 \%)$ & $8.99(5.24-15.41)^{*}$ & $1.78(0.52-6.17)$ \\
\hline \multicolumn{5}{|l|}{ Type of pregnancy } \\
\hline Planned & $111(28.3 \%)$ & $199(50.8 \%)$ & 1 & 1 \\
\hline Unplanned & $12(3.1 \%)$ & $70(17.9 \%)$ & $3.25(1.69-6.26)^{*}$ & $3.80(1.19-12.15)^{*}$ \\
\hline
\end{tabular}




\section{Tesfalidet Tekelab and Balcha Berhanu}

Pregnant women included in the qualitative data reported several reasons for coming early to the health institutions. These reasons included seeking confirmation of early pregnancy, fear of miscarriage, seeking diagnosis and treatment for illness associated with pregnancy, and previous utilization of ANC.

"...... I started at this month of gestation because the health extension workers advised me to take care, as it is important for the health of the mother and the child in addition to that I want to check the health of my baby and confirm pregnancy. In the pregnancy preceded the current, I started ANC check-up at three months of gestation. ANC services are very important for the health of the mother and baby" (A 25 years old, married, parity one, history of one Induced abortion,who booked her first visit at one month of gestation).

Respondents who were booked late for ANC visit stated that they delay to seek care for different reasons such as lack of awareness regarding the importance of early attendance, unplanned or pregnancy out of marriage and no identified illness or health problem during their pregnancy (absence of problem during pregnancy). A 30 years respondent said that

"... I did not know the right time to start antenatal care. I was not aware that it was important to start early. I started the service at seven months of gestation because of illness. I had not experience of previous utilization of ANC for the pregnancy preceding the current. I told to pay for laboratory examination and ultrasound." [Married, parity three, who booked her first visit at seven months of gestation]. Another woman stated "I am student. I became pregnant unintentionally. I did not accept the pregnancy. I concealed the pregnancy for five months from my parents and friends. I am late because I was afraid since I heard that the health professional do not treat single pregnant women well. I paid 3 ETB for examination card" (An 18 years old, never married, parity zero, booked ANC at eight months of her pregnancy).

Almost all health care providers responded that women delay to seek antenatal care if they did not experience discomfort or illness related to their pregnancy. Another reason woman comes late to get labor inducing drugs because they consider iron as labor initiating drugs. Health care provider stated that

"........ I have been worked for nine years in antenatal and delivery units. Pregnant women booked late since previously there was a trend that women perceived that catholic clinic in the surrounding gives labor drugs (iron). Since they consider iron tablet as labor inducing drug. So pregnant women particular from rural area come to take just a labor inducing drug at late pregnancy thus, they booked lately. In addition to that they come for ANC when they encountered health problem." (A midwife who have been working at health center for the past ten years)

\section{DISCUSSION}

The results of this study showed that $31.4 \%$ initiated ANC before 16 weeks of gestation while two third $68.4 \%$ initiated after 16 weeks of gestation. The mean timing was $5.5 \pm 1.8$ months. The finding of this study is higher when compared with study done in Australia on late entry to antenatal care (Trinh et al., 2006). This is probably due to socio-demographic differences between Ethiopia and Australia. But the proportion of women who came for their first ANC visit after 16 weeks of gestation is significantly lower than that of 2011 EDHS result (CSA, 2011). This is because the wide distribution of health posts in each

\section{Sci. Technol. Arts Res. J., Jan-March 2014, 3(1): 108-115}

kebeles and promotion of maternal health care utilization by health extension workers.

The proportion of respondent who visited ANC after 16 weeks of gestation is consistent compared to study done in Hadiya Zone (Zeine et al, 2010). This might be due to socio- demographic similarity between Hadiya Zone and Kembata Tembaro Zone.

Women who were aged 25 years and above were three times more likely to register late compared to those who were less than 25 years $(A O R=3.04,95 \% \mathrm{Cl}=1.05$ 8.81). This finding is inconsistent with studies done in developing countries and Nigeria (Simkhada et al., 2008; Ebeiqbe and Gharoro, 2007). The reason might be young women may have more information about the importance of early antenatal care booking than older women in this study area. Another reason may be young women more careful about their pregnancy and therefore require seeking institutional care than older women. In addition to that younger women is more likely to accept modern health care as they are likely to have greater experience to modern medicine and young women may also be likely to be educated than older women.

Women's educational status is highly correlated with timing of antenatal care. In this study, women that had lower education or none booked later than those with higher education $(\mathrm{AOR}=4.62,95 \% \mathrm{Cl}=1 .-14.24)$., this agrees with studies in developing countries (Trinh et al., 2007; Rhoune et al., 2011; Navaneetham, Dharmalingam 2002). The possible explanation for why education is a key determinant could be that better educated women would likely appreciate the importance of early booking more than the less educated ones. This emphasizes the importance of education on antenatal care.

Consistent with different studies monthly income also was found to be a strong predictor for the late utilization of ANC, respondents income below and 1000ETB were more likely attend ANC lately than monthly income above 1000 ETB. These could be economic status of mother is able to make wise decision about her own than their counterparts (Magadi et al., 2000; Rhoune et al., 2011; Adekanle and Isawumi, 2008; Sharma, 2004).

Higher parity was generally a barrier to adequate use of ANC (Magadi et al., 2000; Overbosch et al., 2004; Paredes et al., 2005; Erci, 2003). This study revealed that women with one parity and above were more likely to register lately compared to those who have no parity. This is in line with studies conducted in Kenya and Addis Ababa which revealed that parity increases the experience of timely booking decreases (Rhoune et al., 2011; Tariku et al., 2010). This is probably due to the fact that women's already developed confidence and may receive that modern health care is not as necessary due to the experience, knowledge accumulated from previous pregnancies and births and consider antenatal care less important.

History of abortion did not showed statistically significant relation with early booking in this study which was found inconsistent with the study done in Turkey (Ciceklioglu et al., 2005). This might be due to small proportion of women who had history of abortion that may not reveal differences. 


\section{Tesfalidet Tekelab and Balcha Berhanu}

Pregnant women who had no experience of previous utilization of ANC for the pregnancy preceding the current nearly sixteen times more likely to book lately than those who had previous experience of ANC (AOR $=15.64$, $95 \% \mathrm{Cl}=1.99-122.95)$. This finding is inconsistent with the previous study done in Addis Ababa (Tariku et al., 2010). This might be due to information received from health care provider about the appropriate time of booking of ANC in present study area.

Distance from home to health institution is not seen as a statistically significant factor for late initiation of ANC in this study $(A O R=1.78,95 \% \mathrm{Cl}=0.52-6.17)$ contrast to other study done in Kenya and Ethiopia (Bahiluet al., 2009, Magadi et al., 2000). This could be due to sampled women being taken from those accessible to health centers and health posts.

The finding of this study revealed that women with unplanned pregnancy were almost four times booked later compared to respondents with planned pregnancy (AOR= $3.80,95 \% \mathrm{Cl}=1.19-12.15)$. This finding is similar with studies done in Kenya, Egypt, Turkey as well as Ethiopia (Jira and Belachew, 2005; Erci, 2003; Youssef et al., 2002; Belay T. Biratu and David P. Lindstrom, 2006; Fekede and Gebremariam, 2007). The reason could be women with unplanned pregnancy or unanticipated pregnancies may initially attempt to deny their pregnancies to themselves and to conceal them from others. As the result women become less motivated to seek ANC early compared to women with their planned pregnancy.

The results of this study showed that pregnant mothers with reasons of perceived correct time, previous experience of ANC and assure or confirming pregnancy were more seen to be booked early than reasons reported as due to illness in current pregnancy, busy by other works, economic factor and unplanned pregnancy which was found as reasons for the late initiation of ANC. This finding is also similar with other studies (Overbosch et al., 2004; Erci, 2003; Tariku et al., 2010; Adamu and Salihu, 2002, Saliku, 2007).

The qualitative part of this study showed that lack of awareness regarding the importance of early attendance, unplanned or pregnancy out of marriage, healthy pregnancy (absence of problem during pregnancy) and not booking when pregnant women come too early for ANC by health care provider were contributing factors for late initiation of antenatal care.

\section{CONCLUSIONS}

In conclusion, the finding of this study showed that $68.6 \%$ women book ANC late indicating that early booking is low. This seems to be because antenatal care is viewed primarily as curative rather than preventive in the study population. The socio-demographic characteristics of respondents such as age, educational status of the women and family income were independent factors for late initiation of ANC. Parity was found as the most predictor for late utilization of ANC while pervious ANC utilization is a positive predictor for timely booking. Women who had no experience of previous utilization of ANC for the pregnancy preceding the current and unplanned pregnancy are positive predictor for late initiation of ANC. The reasons for late booking were reported as busy by other works, economic factors,
Sci. Technol. Arts Res. J., Jan-March 2014, 3(1): 108-115

unplanned pregnancy, illness and not booking when pregnant women come too early by health care provider.

\section{ACKNOWLEDGEMENTS}

We would like to thank Addis Ababa University, College of medicine and Health Sciences for funding this research. We would like also to thank Dr. Amy Bender (University of Toronto) for her constructive comment and valuable suggestion throughout the work process. Our gratitude goes to supervisors, data collectors, respondent who participated on this study and Kembata Tembaro Zoneadministrative.

\section{REFERENCES}

Abou-Zahr, C., Wardlaw T. (2003). Antenatal care in developing countries: promises, achievements and missed opportunities: an analysis of trends, levels and differentials, 1990-2001. Geneva: WHO and UNICEF

Adamu, Y.M. and Salihu H.M. (2002). Barriers to the use of antenatal and obstetric care services in rural Kano, Nigeria. Journal of Obstetrics and Gynaecology 22(6): 600-603.

Adekanle, D.A. and Isawumi, A.I. (2008). Late antenatal care booking and its predictors among pregnant women in South Western Nigeria. Online Journal of Health and Allied Sciences 7(1): 4-7.

Bahilu, T., Abebe, G. and Yohannes, D.(2009). Factors affecting antenatal care utilization in Yem Special Woreda, South Western Ethiopia. Ethiopian Journal of Health Science 19(1).

Belay T. Biratu., David P. Lindstrom. (2006). The influence of husband's approval on women use of prenatal care: Results from Yirgalem and Jimma towns, south west Ethiopia. Ethiopian Journal of Health Development 20(2):85-92.

Ciceklioglu, M., Soyer M.T. and Ocek Z.A. (2005). Factors associated with the utilization and content of prenatal care in a western urban district of Turkey. International Journal for Quality in Health Care; 17(6): 533-539.

CSA, ORC Macro. (2012). Ethiopia Demographic and Health Survey 2011. Addis Ababa, Ethiopia and Calverton, Maryland, USA.

Ebeiqbe, P.N. and Gharoro, E.P. (2007). Obstetric complication, intervention rates and maternofetal outcomes in teenage nullipara in Benin City, Nigeria. Tropical Doctor 37(2): 79-83.

Erci, B. (2003). Barriers to utilization of prenatal care services in Turkey. Journal of Nursing Scholarship 35(3): 269-273.

Federal Democratic Republic of Ethiopia Ministry of Health. (2010). Management protocol on Selected Obstetrics Topics. Pp 9.

Fekede, B., Gebremariam A. (2007). Antenatal care service utilization and factors associated in Jimma town (Southwest Ethiopia). Ethiopian Medical Journal 45(2): 123-133.

Jira, C., Belachew T. (2005). Determinants of Antenatal care utilization in Jimma Town, Ethiopian Journal of Health Sciences 15(1): 49-61.

Kembata Tembaro Zone. (2011). Health Department Indicative Annual Core Plan. Durame.

King, M., Mhlanga, R., De Pinho H. (2006). The context of maternal and child health. South African Health Review 


\section{Tesfalidet Tekelab and Balcha Berhanu}

Health Systems Trust, Durban, South Africa. Pp.107-126 (ISBN: 1-919839-55-0).

Magadi, M., Diamond, I., Madise, N., Smith, P. (2004). Pathways of the determinants of unfavourable birth outcomes in Kenya. Journal of Biosocial Science 36(2):153-176.

Magadi, M.A., Zulu E.M., Brockerhoff, M. (2003). The inequality of maternal health care in urban sub-Saharan Africa in the 1990s. Population Studies 57(3): 347-366.

Magadi, M.A., Madise N.J. and Rodrigues R.N. (2000). Frequency and timing of antenatal care in Kenya: explaining the variations between women of different communities. Social Science and Medicine 51(4):551561.

Navaneetham, K., Dharmalingam, A. (2002). Utilization of maternal health care services in southern India. Social Science and Medicine 55(10):1849-69.

Overbosch, G., Nsowah-Nuamah, N., Van den Boom, G. and Damnyag L. (2004). Determinants of antenatal care use in Ghana. Journal of African Economies 13(2): 277-301.

Paredes, I., Hidalgo, L., Chedraui, P., Palma, J. and Eugenio J. (2005). Factors associated with inadequate prenatal care in Ecuadorianwomen. International Journal of Gynecology and Obstetrics 88(2): 168-172.

Ram Faujdar and Abhishek Singh. (2006). Is antenatal care effective in improving maternal health in rural Uttar Pradesh? Evidence from a district level household survey. Journal of Biosocial Science 38: 433-448.

Reynolds, H.W., Wong, E.L., Tucker, H. (2006). Adolescents' use of Maternal and Child Health Services in Developing Countries. International Family Planning Perspectives 23(1):6-16.

Ochako, R., Fotso, J., Ikamari, L., Khasakhala, A. (2011). Utilization of maternal health services among young women in Kenya: Insights from the Kenya Demographic and Health Survey, 2003. BMC Pregnancy and Childbirth 11(1): 1-9.
Sci. Technol. Arts Res. J., Jan-March 2014, 3(1): 108-115

Saliku, T. (2007). Differences in health seeking behaviour among urban poor women in Nairobi who experienced intended or unintended pregnancies. African Population and Health Research Center; Available at: http://portfolio.du. edu/port/getportfoliofile?fluid=32208 .

Sharma, B. (2004). Utilization of antenatal care services in Nepal. Nepal Population Journal 11(10): 79-97.

Simkhada, B., Teijlingen E.R., Porter, M. and Simkhada, P. (2008). Factors affecting the utilization of antenatal care in developing countries: systematic review of the literature. Journal of Advanced Nursing 61(3): 244-260.

Tariku, A., Melkamu, Y., Kebede, Z. (2010). Previous utilization of service does not improve timely booking in antenatal care: Cross sectional study on timing of antenatal care booking at public health facilities in Addis Ababa. Ethiopian Journal of Health Development; 24(3): 226-233.

Trinh, L.T.T., Dibley, M.J., Byles, J. (2007). Determinants of antenatal care utilization in three rural areas of Vietnam. Public Health Nursing 24(4): 300-310.

Trinh, L.T.T., Rubin, G. (2006). Late entry to antenatal care in New South Wales, Australia. Reproductive Health 3(8). 18.

Wang Wenjuan., Soumya Alva., Shanxiao Wang and Alfredo Fort. (2011). Levels and Trends in the Use of Maternal Health Services in Developing Countries. DHS Comparative Reports No. 26. Calverton, Maryland, USA: ICF Macro.

World Health Organization. (2010). Trends in maternal mortality: 1990 to 2008. Estimates developed by WHO, UNICEF, UNFPA and the World Bank Geneva: WHO.

Youssef , R.M., Moubarak, I.I., Gaffar, Y.A.., Atta, H.Y. (2002). Correlates of unintended pregnancy in Behura governorate, Egypt. Eastern Mediterranean Health Journal 8(4-5): 521-536.

Zeine, A., Mirkuzie, W., Shimeles, O. (2010). Factors influencing antenatal care service utilization in Hadiyazone. Ethiopian Journal of Health Science 20(2): 75-82. 